\title{
Screen printed ZnO UV photoconductive sensor on pencil drawn circuitry over paper
}

\author{
Kamran ul Hasan, Omer Nur and Magnus Willander
}

\section{Linköping University Post Print}

N.B.: When citing this work, cite the original article.

Original Publication:

Kamran ul Hasan, Omer Nur and Magnus Willander, Screen printed ZnO UV photoconductive sensor on pencil drawn circuitry over paper, 2012, Applied Physics Letters, (100), 21, 211104.

http://dx.doi.org/10.1063/1.4720179

Copyright: American Institute of Physics (AIP)

http://www.aip.org/

Postprint available at: Linköping University Electronic Press

http://urn.kb.se/resolve?urn=urn:nbn:se:liu:diva-78686 


\title{
Screen printed $\mathrm{ZnO}$ ultraviolet photoconductive sensor on pencil drawn circuitry over paper
}

\author{
Kamran ul Hasan, ${ }^{\text {a) }}$ Omer Nur, and Magnus Willander \\ Department of Science and Technology (ITN), Linköping University, Campus Norrköping, \\ SE-60 174 Norrköping, Sweden
}

(Received 19 March 2012; accepted 6 May 2012; published online 23 May 2012)

\begin{abstract}
Many applications require a low-cost and large-scale mode of flexible electronics with reasonably high photoresponse that can be detected without high precision measurement systems. We demonstrate a very easy to fabricate $\mathrm{ZnO}$ UV sensor, made on common pencil drawn circuit over a paper. $\mathrm{ZnO}$ nanocrystals were extracted in a high throughput via a simple and green route. This sensor is well capable of detecting UV light and demonstrates features comparable to those of made with complex and expensive techniques. (C) 2012 American Institute of Physics.

[http://dx.doi.org/10.1063/1.4720179]
\end{abstract}

Zinc oxide $(\mathrm{ZnO})$ is substantiating its role as an important material due to its wide variety of potential applications such as light emitting diode (LED), ${ }^{1}$ biosensor, ${ }^{2}$ pressure sensors, ${ }^{3}$ ultraviolet (UV) photodetector, ${ }^{4}$ solar cell, ${ }^{5}$ piezoelectricity and power generation. ${ }^{6} \mathrm{ZnO}$ has many valuable properties, like direct band gap of $3.37 \mathrm{eV}$, large excitons binding energy of $60 \mathrm{meV}$, high thermal/chemical stabilities, piezoelectricity, the option of wet chemical etching, etc. ${ }^{7,8}$ This has led to the demonstration of $\mathrm{ZnO}$ as an alternative material to the nitride semiconductors. $\mathrm{ZnO}$ possesses a rich family of nanostructures such as nanorods, nanowires (NWs), nano belts, nano particles, nano tips, and nanotubes. ${ }^{7,8}$ P-type doping of $\mathrm{ZnO}$ is still a problem that weakens the prospects of a $\mathrm{ZnO}$ p-n homojunction device. ${ }^{9}$ Alternatively, $\mathrm{ZnO}$ is naturally n-doped and does not need external dopants. A $\mathrm{ZnO}$ unipolar device seems to be a very feasible approach.

Most UV sensors have relied on traditional metallic contacts to the $\mathrm{ZnO}$. Typically, the required low cost has been realized by the use of lithographic techniques to produce metal electrodes. Screen-printed (thick-film) graphite electrodes have also been proposed for facilitating cost-effective fabrication process. However, it needs to be noted that some of these electrodes are only disposable in the economic sense, as relevant occupational health and environmental issues may still be in jeopardy. New, easy to make and renewable electrodes are needed for accelerating the realization of large-scale device manufacturing.

We turn towards the ancient form of graphene, known as graphite pencil. The core of a pencil is made of graphite, where graphene sheets are connected together by weak van der Waals attractions with inter-laminar shear strength of only $26 \mathrm{MPa} .{ }^{10}$ While writing with a graphite pencil, we are actually drawing out numerous graphenes from the graphite rod of the pencil. ${ }^{11} \mathrm{We}$ use very simple, pencil drawn interdigitated electrodes and screen printed $\mathrm{ZnO}$ nanocrystals (NCs) to achieve a UV sensor on paper. This graphitic circuitry has many other advantages over conventional metal

\footnotetext{
${ }^{\text {a) }}$ Author to whom correspondence should be addressed. Electronic mail: kamran.ul.hasan@gmail.com.
}

electrodes as it is strong, light, corrosion and heat resistance, besides being cheap and easy to fabricate.

$\mathrm{ZnO} \mathrm{NCs}$ were extracted from the solution bath used for the growth of $\mathrm{ZnO}$ NWs. The NWs are typically grown from solution based technique to fabricate numerous devices, e.g., LEDs, ${ }^{1,12,13}$ biosensors, ${ }^{2,14}$ etc., by uploading the samples upside down in the growth solution (Fig. 1). $\mathrm{ZnO}$ nucleation and growth take place everywhere within the solution but usually only the growth on the sample is utilized whereas the rest of it is wasted. We collected $\mathrm{ZnO}$ NCs from the chemical bath after the growth of NWs on some samples and dried these in powder form, consequently making a printable and semiconducting $\mathrm{ZnO} \mathrm{NC}$ paste by employing a commercial binder.

Zinc nitrate hexahydrate $\left(\mathrm{Zn}\left(\mathrm{NO}_{3}\right)_{2} \cdot 6 \mathrm{H}_{2} \mathrm{O}\right)$ was dissolved in $100 \mathrm{ml}$ deionized (DI) water to attain $0.1 \mathrm{M}$ concentration, and similarly, $0.1 \mathrm{M}$ concentration of hexamethylenetetramine (HMT, $\mathrm{C}_{6} \mathrm{H}_{12} \mathrm{~N}_{4}$ ) was prepared in $100 \mathrm{ml} \mathrm{DI}$ water. $^{12,15,16}$ The solution was kept at $90{ }^{\circ} \mathrm{C}$ for $3 \mathrm{~h}$ and $\mathrm{ZnO}$ NCs were extracted from it and dried in the powder form. XG383 Plastijet XG Varnish was used as a binder to make a $\mathrm{ZnO}$ NC ink for screen printing. Different grade pencils were tested for resistivity and standard 4B pencil was chosen with a line resistance of $\sim 3 \mathrm{M} \Omega$. A 4B pencil typically has 4:1 graphite to clay binder ratio. Our $\mathrm{ZnO} \mathrm{NC}$ film has a horizontal sheet resistance of $\sim 6-7 \mathrm{M} \Omega$; hence there is no need for very high conductive sophisticated electrodes for the sensor fabrication. $\mathrm{ZnO} \mathrm{NC}$ paste was screen printed onto the pencil drawn interdigitated circuit and characterized by scanning electron microscopy (SEM), x-ray diffraction (XRD),

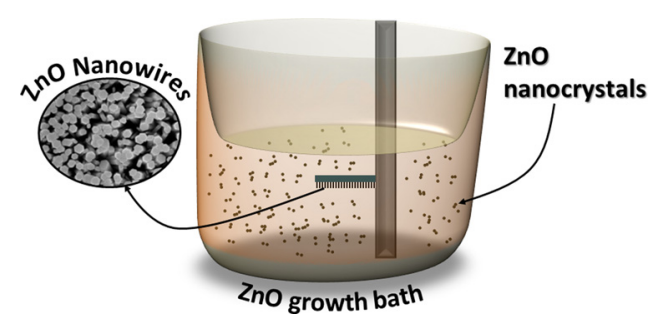

FIG. 1. Solution based growth of $\mathrm{ZnO}$ nanowires with $\mathrm{ZnO}$ nanocrystals coming as a byproduct. 

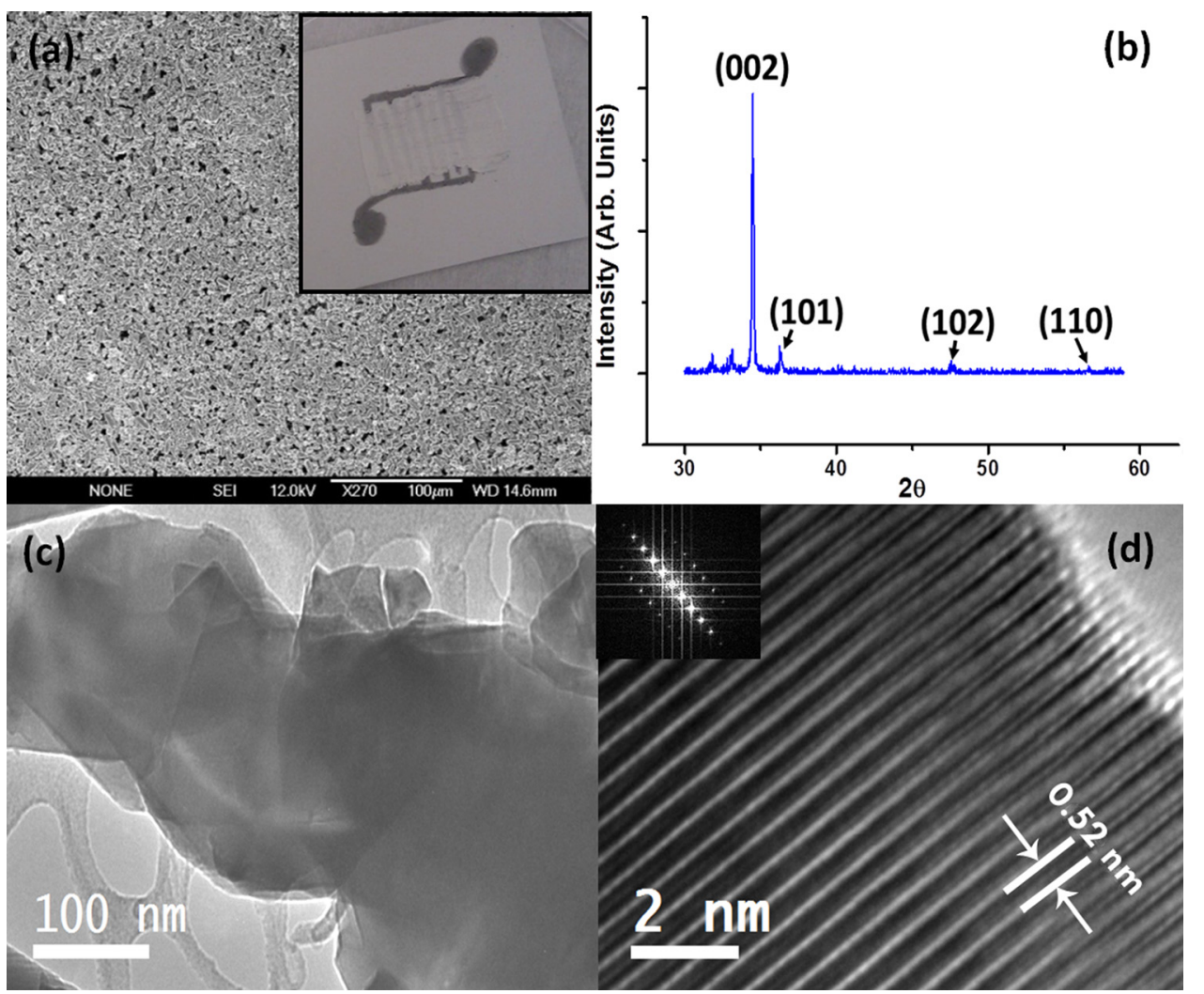

FIG. 2. (a) SEM image of the printed $\mathrm{ZnO}$ NCs with inset showing the picture of the device, (b) XRD of the $\mathrm{ZnO} \mathrm{NCs}$ printed on the paper, (c) low resolution TEM, and (d) HRTEM image of a $\mathrm{ZnO}$ NCs with FFT pattern (inset) showing good crystal quality. and transmission electron microscopy (TEM). ZnO NCs are visible in the SEM image of the screen printed film shown in Fig. 2(a) and the inset is depicting the picture of the pencil drawn paper device. XRD and TEM verify good crystalline quality of the $\mathrm{ZnO}$, as seen in Figs. 2(b)-2(d).

Photoconductive response is a key figure of merit for a photodetector. UV response of our paper devices was measured by using a conventional $365 \mathrm{~nm}$ UV lamp (Figs. 3(a) and 3(b)). The real time ON/OFF switching was measured by turning the UV lamp on and off inside a dark room. The measured photocurrent under the unfocused UV source shows a fast rise upon exposure to UV light and a relatively slower fall once the UV source is turned off, as seen in Fig. 3(b). Photocurrent pulse shows good stability and reversibility. Under dark condition, oxygen molecules are adsorbed on the NC surface and capture free electrons from the n-type $\mathrm{ZnO}$, making negatively charged oxygen ions at the surface. This creates a low conductivity depletion layer near the nanowire surface

$$
O_{2}(g)+e^{-} \rightarrow O_{2}^{-}(a d)
$$

When the UV exposure is made, electron-hole pairs are photo-generated and holes are trapped at the surface by the oxygen ions via surface electron-hole recombination

$$
h^{+}+O_{2}^{-}(a d) \rightarrow O_{2}(g)
$$

Unpaired electrons are left behind which add to the photocurrent. ${ }^{17,18}$

When the UV illumination is switched on or off, the oxygen is desorbed or re-adsorbed in the interfacial region in the premises of the metal contact in Schottky diodes which reduces the barrier height making it act as a valve. Whereas this phenomenon takes place throughout the bulk of the material with no valve like control, for a sensor with an absence of such a barrier. Thus, in our device, a lot of unpaired electrons are generated across the NC film, which results in a
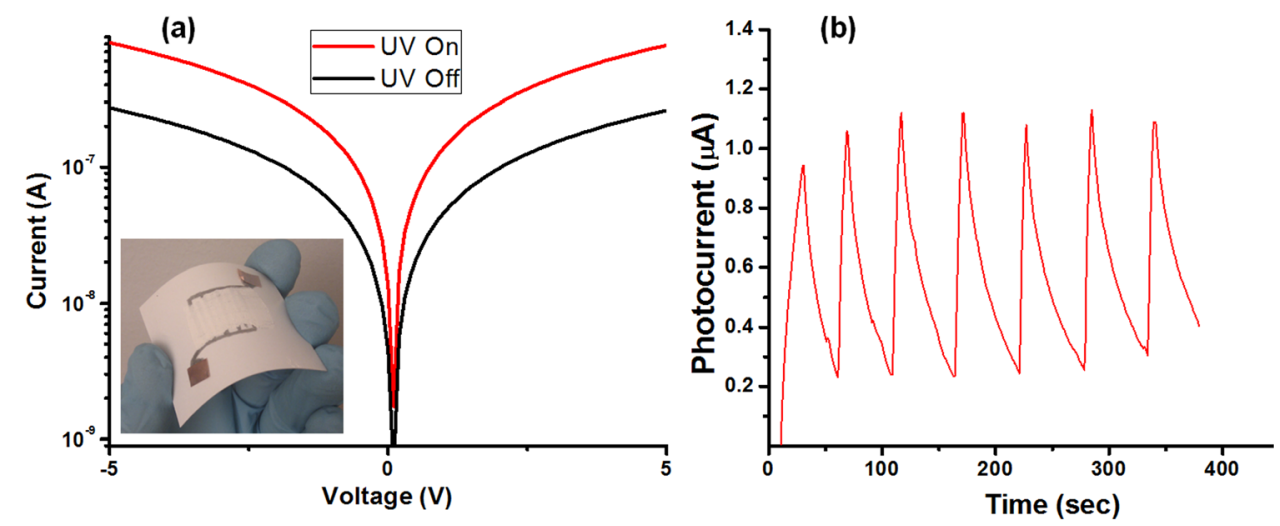

FIG. 3. (a) IV curves of the flexible pencil drawn UV sensor with and without UV illumination. Inset is a photo of a flexible printed UV sensor, (b) timedependent photoresponse of the UV sensor at a bias voltage of $1 \mathrm{~V}$ under UV irradiance from an unfocused UV lamp irradiating at $365 \mathrm{~nm}$. 
rapid rise in the photocurrent. Once the UV exposure is turned off, it takes some time to drain out all those photogenerated electrons. This is the reason behind faster current rise time and much slower photocurrent decay, but it is still fast enough in comparison with recent reports ${ }^{19}$ on $\mathrm{ZnO}$ based flexible UV sensors.

In summary, ZnO NCs were obtained by a green, high throughput and solution-based procedure to fabricate UV sensors. The UV sensors are fabricated through simple approach of screen printing on paper with pencil drawn circuitry. Although these sensors are economical and easy to fabricate, yet they demonstrate characteristics comparable to those made with complex and expensive procedures.

Authors acknowledge the support of Mats O. Sandberg (Acreo Norrköping) for the preparation of $\mathrm{ZnO}$ paste.

${ }^{1}$ N. Alvi, K. ul Hasan, O. Nur, and M. Willander, Nanoscale Res. Lett. 6, 130 (2011).

${ }^{2}$ M. H. Asif, S. M. U. Ali, O. Nur, M. Willander, U. H. Englund, and F. Elinder, Biosens. Bioelectron. 26, 1118 (2010).

${ }^{3}$ X. J. Zheng, X. C. Cao, J. Sun, B. Yuan, Q. H. Li, Z. Zhu, and Y. Zhang, Nanotechnology 22, 435501 (2011).

${ }^{4}$ K. ul Hasan, N. H. Alvi, J. Lu, O. Nur, and M. Willander, Nanoscale Res. Lett. 6, 348 (2011).
${ }^{5}$ A. B. F. Martinson, J. W. Elam, J. T. Hupp, and M. J. Pellin, Nano Lett. 7, 2183 (2007).

${ }^{6}$ G. Zhu, R. Yang, S. Wang, and Z. L. Wang, Nano Lett. 10, 3151 (2010).

${ }^{7}$ D. C. Look, Mater. Sci. Eng., B 80, 383 (2001).

${ }^{8}$ Z. L. Wang, Mater. Sci. Eng. R 64, 33 (2009).

${ }^{9}$ S.-K. Hong, T. Hanada, H. Makino, Y. Chen, H.-J. Ko, T. Yao, A. Tanaka, H. Sasaki, and S. Sato, Appl. Phys. Lett. 78, 3349 (2001).

${ }^{10}$ H. C. Schniepp, J.-L. Li, M. J. McAllister, H. Sai, M. Herrera-Alonso, D. H. Adamson, R. K. Prud'homme, R. Car, D. A. Saville, and I. A. Aksay, J. Phys. Chem. B 110, 8535 (2006).

${ }^{11}$ A. H. Castro Neto, F. Guinea, N. M. R. Peres, K. S. Novoselov, and A. K. Geim, Rev. Mod. Phys. 81, 109 (2009).

${ }^{12}$ S. Kishwar, K. ul Hasan, G. Tzamalis, O. Nur, M. Willander, H. S. Kwack, and D. L. S. Dang, Phys. Status Solidi A 207, 67 (2009).

${ }^{13}$ S. Kishwar, K. ul Hasan, N. H. Alvi, P. Klason, O. Nur, and M. Willander, Superlattices Microstruct. 49, 32 (2010).

${ }^{14}$ A. Fulati, S. M. U. Ali, M. H. Asif, N. Alvi, M. Willander, C. Brännmark, P. Strålfors, S. I. Börjesson, F. Elinder, and B. Danielsson, Sens. Actuators B 150, 673 (2010).

${ }^{15}$ M. Wang, C.-H. Ye, Y. Zhang, G.-M. Hua, H.-X. Wang, M.-G. Kong, and L.-D. Zhang, J. Cryst. Growth 291, 334 (2006).

${ }^{16}$ A. Zainelabdin, S. Zaman, G. Amin, O. Nur, and M. Willander, Cryst. Growth Des. 10, 3250 (2010).

${ }^{17}$ H. Kind, H. Yan, B. Messer, M. Law, and P. Yang, Adv. Mater. 14, 158 (2002).

${ }^{18}$ C. Soci, A. Zhang, B. Xiang, S. A. Dayeh, D. P. R. Aplin, J. Park, X. Y. Bao, Y. H. Lo, and D. Wang, Nano Lett. 7, 1003 (2007).

${ }^{19}$ S. Bai, W. Wu, Y. Qin, N. Cui, D. J. Bayerl, and X. Wang, Adv. Funct. Mater. 21, 4464 (2011). 